\title{
Postmenopozal Osteoporozlu Kadınlarda Kinezyofobinin Yaşam Kalitesi Üzerine Etkisi
}

\author{
The Effect of Kinesiophobia on Quality of Life in Women with Postmenopausal \\ Osteoporosis
}

Türkan TURGAYํ, Pınar GÜNEL KARADENİ²

\begin{abstract}
${ }^{1}$ SANKO Üniversitesi, Tip Fakültesi, Fiziksel Tip ve Rehabilitasyon Anabilim Dalı, Gaziantep, Türkiye
${ }^{2}$ SANKO Üniversitesi, Tip Fakültesi, Biyoistatistik Anabilim Dall, Gaziantep, Türkiye
\end{abstract}

Geliş tarihi: 13.04.2020 Kabul tarihi: 08.06.2020 DOI: 10.17517/ksutfd.719089

\section{Özet}

Amaç: $\mathrm{Bu}$ çalışmada postmenopozal osteoporozlu kadınlarda kinezyofobinin yaşam kalitesi üzerine etkisinin araştırılması amaçlanmıştır.

Gereç ve Yöntemler: Bu vaka kontrol çalışmasına Fiziksel Tip ve Rehabilitasyon polikliniğine başvuran ve 50 yaş ve üzeri postmenpozal osteoporoz tanısı alan 70 kadın hasta ve 58 kadın kontrol dahil edildi. Yaş, vücut kilo indeksi (VKİ), lomber vertebral L1-L4 kemik mineral yoğunluğu (LVKMY), femur boyun kemik mineral yoğunluğu (FBKMY) T-skoru değerleri ve geçirilmiş kırık varlığı kaydedildi. Katılımcıların sırt ağrısı Görsel Analog Skala (GAS) $(0-10 \mathrm{~cm})$ ile değerlendirildi. Yaşam kalitesi değerlendirmesi için QUALEFFO-41 (Quality of Life Questionnaire of the European Foundation for Osteoporosis) ölçeği ve kinezyofobi değerlendirmesi için Tampa Kinezyofobi Ölçeği (TKÖ) kullanıldı.

Bulgular: Çalışmaya katılan 70 osteoporozlu ve 58 kontrol grubu arasında yaş ve VKİ bakımından fark yoktu (p>0.05). Osteoporotik grup ile osteoporotik olmayan grup arasında LVKMY, FBKMY, GAS-sırt ağrısı, QUALEFFO-41 total skor ve TKÖ skoru açısından istatistiksel olarak anlamlı farklılık bulunmuştur ( $\mathrm{p}<0.001)$. QUALEFFO-41'in alt grup ölçekleri değerlendirildiğinde; genel sağlık durumu değerlendirmesi $(\mathrm{p}=0.71)$ dışındaki diğer ağrı, fiziksel fonksiyon, boş zaman ve sosyal aktiviteler, mental fonksiyon parametrelerinde iki grup arasında anlamlı bir fark bulunmuştur $(\mathrm{p}<0.05)$. Osteoporoz grubunda QUALEFFO-41 toplam skoru ile kinezyofobi skoru arasında anlamlı bir korelasyon bulunmuştur $(\mathrm{r}=0.618, \mathrm{p}<0.001)$. Ayrıca, TKÖ ile yaş ve FBKMY arasında anlamlı korelasyon bulunmuştur (sırasıyla; $r=0.621, p<0.00 ; r=-0.477, p<0.001$ ).

Sonuç: Çalışmamızda osteoporoz hastalarında ileri yaş ve düşük FBKMY değerlerinin kinezyofobiyi arttırarak yaşam kalitesini azalttığı gösterilmiştir.

Anahtar Kelimeler: Kinezyofobi, Osteoporoz, Yaşam kalitesi 


\begin{abstract}
Objective: In this study, it was aimed to investigate the effect of kinesiophobia on quality of life in women with postmenopausal osteoporosis.

Material and Methods: This case control study included 70 females who were admitted to the Physical Medicine and Rehabilitation outpatient clinic and were diagnosed with postmenopausal osteoporosis aged 50 and over, and 58 female controls. Age, body mass index (BMI), lumbar vertebral L1-L4 bone mineral density (LVBMD), femoral neck bone mineral density (FNBMD) T-score values and history of fracture were recorded. Back pain of the participants was evaluated via Visual Analogue Scale (VAS) (0-10 cm). QUALEFFO-41 (Quality of Life Questionnaire of the European Foundation for Osteoporosis) scale was used for quality of life assessment and Tampa Kinesiophobia Scale (TKS) was used for assessment of kinesiophobia.
\end{abstract}

Results: There was no difference in age and BMI between 70 osteoporosis and 58 control groups in the study (p>0.05). A statistically significant difference was found between the osteoporotic and the non-osteoporotic group in terms of LVBMD, FNBMD, VAS-back pain, QUALEFFO-41 total score and TKS score $(\mathrm{p}<0.001)$. When subgroup scales of QUALEFFO-41 was evaluated, a significant difference was found between the two groups in the parameters of pain, physical function, leisure time and social activities, mental function $(p<0.05)$, except general health status $(p=0.71)$. A significant correlation was found between QUALEFFO-41 total score and kinesiophobia score in the osteoporosis group $(\mathrm{r}=0.618, \mathrm{p}<0.001)$ also between TKS and age and FNBMD $(\mathrm{r}=0.621, \mathrm{p}<0.00, \mathrm{r}=-0.477, \mathrm{p}<0.001$, respectively).

Conclusion: In our study, it has been revealed that high age and low FNBMD values in osteoporosis patients decrease the quality of life by increasing kinesiophobia.

Key words: Kinesiophobia, Osteoporosis, Quality of life

Yazışma Adresi: Türkan TURGAY SANKO Üniversitesi, Tıp Fakültesi, Fiziksel Tip ve Rehabilitasyon Anabilim Dalı. Gaziantep, Türkiye

Tel: +90 3422116500 Fax: +90 3422115010 e-mail: turkanharunlar@hotmail.com ORCID No (Sirasıly): 0000-0002-6348-3340, 00000003-3768-2351 


\section{GİRIŞ}

Osteoporoz, düşük kemik yoğunluğu ve kemik dokusunun mikromimarisinde bozulma sonucu kemik kırılganlığının ve kırık riskinin artması ile karakterize sistemik bir iskelet hastalığıdır (1). Türkiye'de osteoporoz prevalansı \%2 olup, 50 yaş üstü bireylerde kalça kırığı insidansı 10.000'de 13’tür (2). Bir kişinin yaşam boyunca kazanacağ 1 doruk kemik kütlesi 2535 yaşlarıdır. İleri yaş ve kadın cinsiyet, osteoporoz ve osteoporoza bağlı kırık riskini arttıran en önemli faktörlerdir (3). Osteoporozdan korunmada risk faktörlerinin belirlenmesi ve azaltılması, diyet ve medikal tedavinin yanında düşmeye bağlı kırıkların önlenmesi en temel tedavi yaklaşımı olarak bilinmektedir. Vertebral kırıklar kadınlarda erkeklerden 10 kat daha sık görülür (4). Kadınlarda sıklıkla radius başı ve vertebral kompresyon kırıkları görülür. Özellikle kalça k1rıkları önemli fiziksel, psikolojik, sosyal ve ekonomik yüke yol açar (5). Vertebral kompresyon kırıklarının çoğu günlük rutin işler sırasında oluşur ancak 1/3'ü ağrılı olup \%10'dan daha azı hastanelere başvurmaktadır. Bu durum hastalarda fiziksel aktivite sırasında düşme ve kırık riskinin artma olasılığına ilişkin mantıksız bir inanç nedeniyle kinezyofobi yani hareket etme korkusu ile sonuçlanabilir (6).Hem kazanılmış hem de doğuştan olan korku hissi, beynin temporal lobunda bulunan ve birkaç subkortikal çekirdekten oluşan amigdala kompleksi tarafından kontrol edilmektedir (7). Kinezyofobi beynin özellikle limbik sisteminde yer alan olan amigdala ve insula bölgesi ile ilişkilidir. Amigdala ve insula bölgeleri başta korku olmak üzere duygular, hafıza ve sağkalım ile ilgili dürtülerin denetiminden sorumlu anatomik bölgeler olarak bilinmektedir (8). Kori ve ark. kinezyofobiyi yaralanmaya karşı duyarlılık ve kırılganlık inancından oluşan olumsuz etkilere sahip hareket ve aktivite korkusu olarak tanımlamışlardır (9).Kas iskelet sistemi hastalıklarının rehabilitasyonunda kinezyofobinin olumsuz bir rol oynadığ 1 tespit edilmiştir (10). İleri yaş, beslenme yetersizliği, uzamış yatak istirahati, bası yaraları, yürüme bozuklukları, istemsiz kilo kaybı, psikolojik ve kognitif bozukluklar, çoklu ilaç kullanımı, genel kas güçsüzlüğü, ağrı, ev dişına az çıkma, artan kinezyofobi bu hastalarda yaşam kalitesinde giderek bozulmaya yol açar $(11,12)$. Günümüzde kemik kaybını önlemek için immobilizasyondan korunmak ve uygun fiziksel aktivite osteoporozun en önemli tedavi yöntemidir (13). Kinezyofobi fiziksel aktiviteyi yavaş bir şekilde arttırarak ve kişiye özel egzersiz programları ile bedensel ve emosyonel stabilite sağlayarak kontrol altına alınabilir. Bugüne kadar osteoporoz hastalarında kinezyofobi ve yaşam kalitesi arasındaki ilişkiyi değerlendiren çok az çalışma mevcuttur. Bu çalışmada osteoporotik hastalarda düşme korkusunun yol açtığı sosyal izolasyon ve inaktivitenin yaşam kalitesi üzerine etkisinin gösterilmesi amaçlanmıştır.

\section{GEREÇ VE YÖNTEMLER}

$\mathrm{Bu}$ vaka kontrol çalışması için SANKO Üniversitesi Klinik Araştırmalar Etik Kurulu'ndan izin alındı (Karar No:2020/0401). SANKO Üniversitesi Sani Konukoğlu Uygulama ve Araştırma Hastanesi, Fiziksel Tip ve Rehabilitasyon polikliniğine
Şubat-Nisan 2020 tarihlerinde başvuran ve postmenopozal osteoporoz tanısı alan 50 yaş ve üzeri 70 hasta ile postmenopozal osteoporoz tanisı almayan 58 kontrol dahil edildi. Kontrol grubu yaş ve VKİ bakımından vaka grubu ile benzer şekilde seçildi. Çalışmada her bir grup için ayrı olarak hazırlanan aydınlatılmış onam formu katılımcılara okunarak imza alındı. Katılımcıların kemik mineral yoğunluğu (KMY) ölçümü çift enerjili X-1şınlı absorpsiyometri (Dual Energy X-ray Absorptiometry; DXA) (GE-Lunar DPX NT DEXA Scanner cihazı) ölçüm standartlarına göre belirlendi. DXA, lomber omurga ve kalçada KMY' yi ölçmek için referans yöntemdir. Kemik kuvveti BMD ile güçlü bir korelasyon gösterir. Postmenopozal kadınlarda KMY sonuçları T skoru olarak bildirilir. T-skoru, genç kadınlarda aynı bölge ortalama KMY' nin üstünde veya altında ölçülen KMY değerinin standart sapma sayısıdır. Dünya Sağlık Örgütü sınıflandırma sistemine göre lomber vertebral kemik mineral yoğunluğu L1-L4 (LVKMY) ve femur boyunkemik mineral yoğunluğu (FBKMY) T skorlar1 $\leq-2,5$ olan bireyler osteoporoz, T skoru -1.0 ile -2.5 arasında olanlar ise osteopeni tanısı almaktadır (14). Tüm olguların yaş, cinsiyet, vücut kilo indeksi (VKİ), lomber bölgeden L1-L4, femur boyun KMY $\left(\mathrm{gr} / \mathrm{cm}^{2}\right)$ T-skoru değerleri ile geçirilmiş kırık varlığı kaydedildi. Katılımcıların sırt ağrısı Görsel Analog Skala (GAS) (0-10 cm) ile değerlendirildi (15). Yaşam kalitesi değerlendirmesi için Türkçe versiyonu ve güvenirlik çalışması yapılmış QUALEFFO-41 (Quality of Life Questionnaire of the European Foundation for Osteoporosis) ölçeği kullanıldı (16). Ağrı (5 madde), fiziksel fonksiyon (17 madde), sosyal etkinlik (7 madde), genel sağlık değerlendirmesi ( 3 madde) ve zihinsel fonksiyon (9 madde) olmak üzere 5 alt ölçekten oluşan bu ankette her bir alt grup ve toplam sonuç 0-100 arasında puan almaktadır. 0 puan en iyi sağlık durumunu gösterirken, puanların yükselmesi yaşam kalitesinin kötü olduğu anlamına gelmektedir. Ağrı temelli hareket limitasyonu oluşturan korku nedeniyle kaçınma, iş ile ilişkili aktivitelerde korku, hareket veya tekrar yaralanma korkusu esas alınmış olan ve Türkçe versiyonu ve ölçeğin güvenirlik çalışması yapılmış Tampa Kinezyofobi Ölçeği (TKÖ) ise kinezyofobi değerlendirmesinde kullanıldı (17). TKÖ, hareket ya da tekrar yaralanma korkusunu ölçmek amacıyla geliştirilen 17 soruluk bir ölçektir. Ölçek, iş ile ilişkili aktivitelerde, yaralanma/tekrar yaralanma ve korku-kaçınma parametrelerini içerir. Ölçekte 4 puanlık Likert puanlaması (1=Kesinlikle katılmıyorum, 4=Tamamen katılıorum) kullanılmaktadır. $4,8,12$ ve 16 . maddenin ters çevrilmesinden sonra toplam bir puan hesaplanmaktadır. Bu değerlendirmede birey 17-68 arasında bir skor almaktadır. Ölçekte kişinin aldığı puanın yüksek oluşu kinezyofobisinin de yüksek olduğunu göstermektedir. Çalışmaya iletişim kurmayı engelleyecek mental problem, malignite ve kemik metabolizmasını engelleyecek başka bir hastalığı (multiple myelom, paget hastalığ 1 , osteomalazi, renal osteodistrofi) olanlar ile prematur menapoz öyküsü olanlar kadın hastalar dahil edilmemiştir. 


\section{İstatistiksel Analiz}

Verilerin analizinde IBM SPSS Statistic 23 programın kullanılmıştır. Tanımlayıcı istatistik olarak verinin uygunluğuna göre ortalama ve standart sapma ya da medyan ve minmax değerleri verilmiştir. Verilerin normal dağılıp dağılmadığ1 Kolmogorov-Smirnov testi ile değerlendirilmiştir. Grup karşılaştırmalarında; normal dağılan veriler için bağımsız örnekler t-testi, normal dağılmayan veriler için Mann-Whitney U testi kullanılmıştır. İki sürekli veri arasındaki ilişki Pearson's correlation coefficient ile değerlendirilmiştir. $\mathrm{p}<0.05$ istatistiksel olarak anlamlı kabul edilmiştir.

\section{BULGULAR}

Çalışmaya katılan 70 osteoporozlu ve 58 kontrol grubu arasında yaş ve VKİ bakımından fark yoktu ( $p>0.05$ ) (Tablo 1). Osteoporoz hastalarının 15 'i sadece torakal, 10 'u sadece lomber ve 3 'ü hem torakal hem lomber seviyede vertebral kırık ile 6'sı geçirilmiş femoral kırık öyküsüne sahipti. Osteoporotik grup ile osteoporotik olmayan grup arasında LVKMY, FBKMY, GAS-sırt ağrısı, QUALEFFO-41 total skor ve TKÖ skoru açısından istatistiksel olarak anlamlı farklılık bulunmuştur $(\mathrm{p}<0.001)$. Grupların klinik özellikleri ile QUALEFFO-41 total skor ve TKÖ puan ortalamaları Tablo 1'de verilmiştir. QUALEFFO-41'in alt grup ölçekleri ile tek tek değerlendirildiğinde; genel sağlık değerlendirmesi dışındaki diğer ağrı, fiziksel fonksiyon, boş zaman ve sosyal aktiviteler, mental fonksiyon alanlarında iki grup arasında anlamlı bir fark bulunmuştur $(\mathrm{p}<0.001)$ (Tablo 2). Osteoporoz grubunda QUALEFFO-41 toplam skoru ile kinezyofobi skoru arasinda anlamlı bir ilişki bulunmuştur $(\mathrm{r}=0.618, \mathrm{p}<0.001)$ (Tablo 3). Ayrıca, TKÖ ile yaş ve FBKMY arasında anlamlı korelasyon bulunmuştur (sırasıyla; $\mathrm{r}=0.621, \mathrm{p}<0.00 ; \mathrm{r}=-0.477, \mathrm{p}<0.001$ ) (Tablo 3). Yaş arttıkça ve FBKMY azaldıkça kinezyofobinin arttığ1 ve yaşam kalitesinin azaldığı görülmüştür.

\section{Tablo 1. Katılımciların Demografik Özellikleri}

\begin{tabular}{|l|l|l|l|}
\hline Özellikler & Osteoporotik hastalar (70) & $\begin{array}{l}\text { Kontrol grubu } \\
\mathbf{( 5 8 )}\end{array}$ & p-değerleri \\
\hline Yaş, yıl & $69.86 \pm 9.43$ & $67.05 \pm 7.92$ & $0.074^{\mathrm{a}}$ \\
\hline VKİ, kg/m & $27.9 \pm 5.5$ & $0.117^{\mathrm{a}}$ \\
\hline GAS-sırt ağrisı & $29.4 \pm 5.6$ & $4.36 \pm 1.02$ & $<0.001^{\mathrm{a}^{*}}$ \\
\hline LVKMY & $6.14 \pm 1.61$ & $-1.1(-2.1 ; 0.8)$ & $<0.001^{\mathrm{b}^{*}}$ \\
\hline FBKMY & $-2.80(-4.4 ; 0.0)$ & $-0.9(-1.8 ; 1.5)$ & $<0.001^{\mathrm{b}^{*}}$ \\
\hline $\begin{array}{l}\text { VKİ: Vücut Kilo İndeksi; GAS: Görsel Analog Skala; Lomber Vertebral L1-L4 Kemik Mineral Yoğunluğu (LVKMY), Femur Boyun Kemik Mineral Yo- } \\
\text { ğunluğu (FBKMY). aBağımsız gruplar t-testi, bMann-Whitney U testi, Ortalama } \pm \text { Standart Sapma; Medyan (min;maks), }{ }^{*}<00.05 .\end{array}$ \\
\hline
\end{tabular}

Tablo 2. Hasta ve Kontrol Gruplarının Yaşam Kalitesi ve Kinezyofobi Düzeyinin Karşılaştırılıası

\begin{tabular}{|c|c|c|c|}
\hline Parametreler & $\begin{array}{l}\text { Osteoporotik hastalar } \\
\text { (70) }\end{array}$ & $\begin{array}{l}\text { Kontrol grubu } \\
(58)\end{array}$ & p-değerleri \\
\hline QUALEFFO-Ăgrı & $58.23 \pm 14.94$ & $44.76 \pm 12.10$ & $<0.001^{\star}$ \\
\hline $\begin{array}{l}\text { QUALEFFO-Günlük yaşam } \\
\text { aktiviteleri }\end{array}$ & $58.50 \pm 13.52$ & $48.74 \pm 11.07$ & $<0.001^{\star}$ \\
\hline QUALEFFO-Ev işleri & $59.29 \pm 13.79$ & $48.83 \pm 12.18$ & $<0.001^{\star}$ \\
\hline QUALEFFO- Mobilite & $57.09 \pm 15.16$ & $50.43 \pm 14.81$ & $0.014^{*}$ \\
\hline $\begin{array}{l}\text { QUALEFFO-Boş zaman, } \\
\text { Sosyal aktivite }\end{array}$ & $56.53 \pm 17.99$ & $43.14 \pm 10.98$ & $<0.001^{\star}$ \\
\hline $\begin{array}{l}\text { QUALEFFO-Genel sağlık } \\
\text { algısı }\end{array}$ & $54.41 \pm 15.12$ & $51.55 \pm 11.99$ & 0.245 \\
\hline $\begin{array}{l}\text { QUALEFFO-Mental } \\
\text { fonksiyon }\end{array}$ & $54.30 \pm 17.96$ & $44.07 \pm 12.19$ & $<0.001^{\star}$ \\
\hline QUALEFFO-Total skor & $56.91 \pm 12.31$ & $47.31 \pm 8.69$ & $<0.001^{\star}$ \\
\hline TKÖ & $45.54 \pm 11.10$ & $29.09 \pm 7.04$ & $<0.001^{*}$ \\
\hline
\end{tabular}




\begin{tabular}{|c|c|c|c|c|c|c|c|c|c|c|c|c|c|}
\hline & & VKİ & Yaş & LVKMY & FBKMY & Ağrı & $\begin{array}{l}\text { Günlïk } \\
\text { yaşam } \\
\text { aktiviteleri }\end{array}$ & Ev işleri & Mobilite & $\begin{array}{l}\text { Boş } \\
\text { zaman, } \\
\text { Sosyal } \\
\text { aktivite }\end{array}$ & $\begin{array}{l}\text { Genel } \\
\text { sağlık } \\
\text { algısı }\end{array}$ & $\begin{array}{l}\text { Mental } \\
\text { fonksiyon }\end{array}$ & $\begin{array}{l}\text { Total } \\
\text { skor }\end{array}$ \\
\hline \multirow[t]{2}{*}{ VKİ } & $\mathrm{r}$ & - & 0.045 & 0.251 & 0.181 & 0.042 & 0.012 & 0.123 & 0.133 & 0.015 & -0.101 & -0.048 & 0.026 \\
\hline & $\mathrm{p}$ & - & 0.713 & $0.036^{\star}$ & 0.134 & 0.729 & 0.922 & 0.310 & 0.274 & 0.900 & 0.406 & 0.693 & 0.830 \\
\hline \multirow[t]{2}{*}{ Yaş } & $\mathrm{r}$ & - & - & -0.037 & -0.433 & 0.133 & 0.559 & 0.577 & 0.655 & 0.526 & 0.570 & 0.746 & 0.683 \\
\hline & $\mathrm{p}$ & - & - & 0.762 & $<0.001^{\star}$ & 0.273 & $<0.001^{\star}$ & $<0.001^{\star}$ & $<0.001^{\star}$ & $<0.001^{\star}$ & $<0.001^{\star}$ & $<0.001^{\star}$ & $<0.001^{\star}$ \\
\hline \multirow[t]{2}{*}{ LVKMY } & $\mathrm{r}$ & - & - & - & -0.004 & 0.047 & -0.141 & -0.048 & -0.078 & -0.072 & 0.040 & -0.047 & -0.051 \\
\hline & $\mathrm{p}$ & - & - & - & 0.974 & 0.701 & 0.246 & 0.695 & 0.522 & 0.554 & 0.742 & 0.699 & 0.677 \\
\hline \multirow[t]{2}{*}{ FBKMY } & $\mathrm{r}$ & - & - & - & - & -0.158 & -0.415 & -0.225 & -0.305 & -0.196 & -0.298 & -0.351 & -0.353 \\
\hline & $\mathrm{p}$ & - & - & - & - & 0.193 & $<0.001^{\star}$ & 0.061 & $0.010^{*}$ & 0.104 & $0.012^{*}$ & $0.003^{*}$ & $0.003^{*}$ \\
\hline \multirow[t]{2}{*}{ TKÖ } & $\mathrm{r}$ & 0.065 & 0.621 & 0.087 & -0.477 & 0.297 & 0.490 & 0.555 & 0.553 & 0.488 & 0.487 & 0.561 & 0.618 \\
\hline & $\mathrm{p}$ & 0.595 & $<0.001^{*}$ & 0.473 & $<0.001^{\star}$ & 0.013 & $<0.001^{\star}$ & $<0.001^{\star}$ & $<0.001^{\star}$ & $<0.001^{*}$ & $<0.001^{*}$ & $<0.001^{*}$ & $<0.001^{\star}$ \\
\hline \multirow{2}{*}{$\begin{array}{l}\text { GAS-sırt } \\
\text { ağrısı }\end{array}$} & $\mathrm{r}$ & -0.066 & 0.170 & 0.110 & -0.269 & 0.735 & 0.475 & 0.414 & 0.493 & 0.443 & 0.476 & 0.322 & 0.602 \\
\hline & $\mathrm{p}$ & 0.589 & 0.158 & 0.365 & $0.024^{*}$ & $<0.001^{\star}$ & $<0.001^{\star}$ & $<0.001^{\star}$ & $<0.001^{*}$ & $<0.001^{*}$ & $<0.001^{*}$ & $0.007^{\star}$ & $<0.001^{\star}$ \\
\hline \multicolumn{14}{|c|}{$\begin{array}{l}\text { VKİ: Vücut Kilo İndeksi; Lomber Vertebral L1-L4 Kemik Mineral Yoğunluğu (LVKMY), Femur Boyun Kemik Mineral Yoğunluğu } \\
\text { (FBKMY); TKÖ: TAMPA Kinezyofobi Ölçeği. } \\
\text { r: korelasyon katsayısı, }{ }^{\star} p<0.05\end{array}$} \\
\hline
\end{tabular}

\section{TARTIŞMA}

$\mathrm{Bu}$ çalışmada kontrol grubuna göre osteoporozlu olguların ileri yaș, yüksek BMI ve düșük BMD değerleriyle uyumlu daha fazla kinezyofobi ve daha kötü yaşam kalitesine sahip olduğu gösterilmiştir. Osteoporozlu olgularda yaş, kalça osteoporozu ve kinezyofobi arttıkça yaşam kalitesinin azaldığı gözlenmiştir.

Kinezyofobi, yaralanmaya yatkınlık inancı nedeniyle gelişen hareket korkusu olarak tanımlanmaktadır (18). Yapılan çalışmalarda bel ve boyun ağrıları gibi kas-iskelet sistemi bozukluklarının kinezyofobi ile ilişkili olduğu gösterilmiştir. Hareket kısıtlılığına bağlı fonksiyonel engellilik kinezyofobi ile ilişkili en önemli faktörler arasında yer alır $(19,20)$.

İleri yaş gibi osteoporoz ile ilişkili birçok risk faktörü ve bu risklerin osteoporoz prevalansını, kırık ve düşme riskini azaltıp azaltmadığını belirlemek oldukça önemlidir. Bu çalışmada osteoporozlu hasta grubumuzun daha yaşlı olması, ileri yaş ve komorbiditelerin neden olduğu bir hareketsizlik döngüsüne, artan kemik ve kas kaybının da eklenmesi ile açıklanabilir.

QUALEFFO-41 ölçeği osteoporotik kişinin sağlı̆̆ını; ağrı, fiziksel fonksiyon, sosyal yaşam, genel sağlık ve zihinsel fonksiyon gibi beş parametrede değerlendiren bir ankettir. Yap1lan çalışmalar anksiyete, depresyon, zihinsel rahatsızlık gibi fiziksel semptomların genel kas iskelet ağrısı ile ilişkili olarak hareket korkusuna neden olabileceğini göstermiştir $(21,22)$. $\mathrm{Bu}$ çalışmada osteoporotik bireylerde immobilizasyonun daha çok kinezyofobiye neden olduğu sonucu bulunmuştur. Günendi ve ark, osteoporoz hastalarında kinezyofobinin ya- şam kalitesi üzerine olumsuz etkisini göstermiştir (23). Bu çalışmada da osteoporoz hastalarında QUALEFFO-41 ölçeği kullanılarak değerlendirilen tüm alt parametrelerde kinezyofobi ile orta düzeyde bir korelasyon olduğu gözlenmiştir.

Ağrı kaynaklı hareketsizliğin yaşla birlikte arttığı, daha sık düşme ve artmış kırılganlık riski ile ilişkili olduğu gösterilmiştir (24). Ancak düşük travmalı kırıkların \%80'inden fazlasının asemptomatik osteopenik bireylerde meydana geldiğini gösteren çalışmalar da mevcuttur (25). Bu çalışmada postmenopozal osteoporoz hastalarından 15 'i sadece torakal, 10'u sadece lomber, 3'ü hem torakal hem lomber seviyede vertebral kırık ve 6'sı geçirilmiş femoral kırık öyküsüne sahipti. Osteoporotik kırıkların yaşam kalitesinde bozulmaya yol açtığını gösteren birçok çalışma mevcuttur $(26,27)$. Bu kırıklar hareketsizliğe, günlük aktivitelerde ve zihinsel fonksiyonlarda bozulmaya yol açabilirler (28). Bu çalışma da osteoporozlu hastalarda sırt ağrısının yaşam kalitesi parametrelerini olumsuz etkilediğini göstermiştir (Tablo 3).

Literatürde düşük FBKMY ve LVKMY değerlerinin QUALEFFO ile değerlendirilen yasam kalitesi üzerine etkisinde oldukça çelişkili sonuçlar bulunmaktadır $(29,30)$. Bu çalışmada düşük FBKMY değerlerinin kinezyofobiyi arttırması ile yaşam kalitesini olumsuz etkilediği tespit edilmiştir.

Oksuz ve ark, osteoporozlu hastalarda pilates egzersiz programının kinezyofobi üzerindeki etkisini değerlendirmiş ve egzersiz programının kinezyofobiyi iyileştirdiğini bulmuşlardır (31). Fiziksel aktivitenin osteoporoz tedavisinde birçok önleyici ve terapötik etkisi olduğu bilinmektedir. Bu çalışmanın sonuçları yüksek VKİnin osteoporozlu hastalar- 
da yaşam kalitesini etkilemediğini ancak kontrol grubunda kinezyofobiyi arttırdığını göstermiştir. Osteoporozda düşme ve kırık riskini azaltmak için kilo verme aktiviteleri oldukça önemlidir. Osteoporotik kalça kırı̆̆ı aktif yaşam tarzı olan kişilerde daha az görülür (2). Bu nedenle, osteoporozlu hastalarda fiziksel aktiviteyi sınırlayabilecek korku ve kaçınma davranışları dikkate alınmalıdır. Kas gücü ve postural dengeye odaklanan egzersiz programları osteoporozlu hastalarda düşme ve kırık risk faktörlerini azaltmada oldukça etkili bulunmuştur $(32,33)$.

Çalışmamızda bazı kısıtlılıklar bulunmaktadır. İlk olarak bu çalışmanın kapsamında ele alınmayan başkaca faktörler de osteoporoz hastalarında kinezyofobi ve yaşam kalitesi arasındaki ilişkiyi etkileyebilir. İkinci sınırlama, TKÖ anketinin osteoporozlu kişilerde kullanım geçerliliğinden yoksun olmasıdır, çünkü TKÖ ağrı temelli hareket etme korkusu olan kişiler için geliştirilmiş bir değerlendirmedir. Ayrıca örneklem büyüklüğünün az olması bu çalışmayı kısıtlayan diğer bir faktör olarak karşımıza çıkmaktadır.

Günümüzde yaşam kalitesinin belirlenmesi, tedavi stratejilerini saptamada ve tedavi etkinliğini değerlendirmede önemli bir yer tutmaktadır. Sonuç olarak, bu çalışmada osteoporoz hastalarında ileri yaş ve düşük FBKMY değerlerinin kinezyofobiyi arttırarak yaşam kalitesini azalttığı gösterilmiştir. Dolayısıyla bu çalışmanın bulguları osteoporoz hastalarını analiz ve tedavi ederken daha bütüncül bir yaklaşıma ihtiyaç olduğunu vurgulamaktadır. Osteoporozlu hastaların tedavisi ile ilgilenen sağlık personelinin tedavi planından önce hastalara gerekli eğitimi vermesi, hastalarda kilo kontrolü, günlük yaşam aktiviteleri ve fiziksel aktivite düzeyi ile ilgili farkındalıklarını arttırması önerilir. Bu yönde daha geniş çaplı başkaca çalışmalara ihtiyaç bulunmaktadır.

\section{Destekleyen Kuruluş: Yok.}

Çıkar Çatışması: Yok.

Etik Onay: Çalışma için SANKO Üniversitesi Klinik Araştırmalar Etik Kurulu'ndan izin alındı (Karar No: 2020/04-01).

Aydınlatılmış Onam: Çalışmada her bir grup için ayrı olarak hazırlanan aydınlatılııs onam formu katılımcılara okunarak imza alındı.

\section{KAYNAKLAR}

1. http://www.iofbonehealth.org

2. Tuzun S, Eskiyurt N, Akarirmak U, Saridogan M, Senocak M, Johansson H, et al. Turkish Osteoporosis Society. Incidence of hip fracture and prevalence of osteoporosis in Turkey: the FRACTURK study. Osteoporos Int. 2012;23:949-55.

3. Chew CK, Clarke BL. Causes of low peak bone mass in women. Maturitas. 2018;111(5):61-68.

4. Oleksik A, Lips P, Dawson A, Minshall ME, Shen W, Cooper C, et al. Health-related quality of life in postmenopausal women with low BMD with or without prevalent vertebral fractures. J Bone Miner Res. 2000;15: 1384-92.
5. Mohd-Tahir NA, Li SC. Economic burden of osteoporosis-related hip fracture in Asia: a systematic review. Osteoporos Int. 2017;28:2035-44.

6. Larsson C, Ekvall Hansson E, Sundquist K, Jakobsson U. Impact of pain characteristics and fear-avoidance beliefs on physical activity levels among older adults with chronic pain: a population-based, longitudinal study. BMC Geriatr. 2016;16:50.

7. Riccio A, Li Y, Moon J, et al. Essential role for TRPC5 in amygdala function and fear-related behavior. Cell. 2009;137(4):76172.

8. Phelps EA, O'Connor KJ, Gatenby JC, et al. Activation of the left amygdala to a cognitive representation of fear. Nature neuroscience. 2001;4(4):437.

9. Kori SH, Miller RP, Todd DD. Kinesiophobia: a new view of chronic pain behavior. Pain Res Manag. 1990;3:35-43.

10. Vlaeyen JW, Linton SJ. Fear-avoidance and its consequences in chronic musculoskeletal pain: a state of the art. Pain. 2000 Apr;85(3):317-32.

11. Fried LP, Tangen CM, Walston J, Newman AB, Hirsch C, Gottdiener J, et al. Cardiovascular Health Study Collaborative Research Group. Frailty in older adults: evidence for a phenotype. J Gerontol A Biol Sci Med Sci. 2001;56: 146-157.

12. Gunendi Z, Eker D, Tecer D, Karaoglan B, Ozyemisci Tas Kıran O. Is the word "osteoporosis" a reason for kinesiophobia? Eur J Phys Rehab Med. 2018;54(5):671-5.

13. Kanis JA, McCloskey EV, Johansson H, Cooper C, Rizzoli R, Reginster JY; Scientific Advisory Board of the European Society for Clinical and Economic Aspects of Osteoporosis and Osteoarthritis (ESCEO) and the Committee of Scientific Advisors of the International Osteoporosis Foundation (IOF). European guidance for the diagnosis and management of osteoporosis in postmenopausal women. Osteoporos Int.2013;24:23-57.

14. World Health Organization. Assessment of fracture risk and its application to screening for postmenopausal osteoporosis. Report of a WHO study group. Geneva, World Health Organization, 1994 (WHO Technical Report Series, No. 843).

15. Hawker GA, Mian S, Kendzerska T, French M. Measures of adult pain: Visual Analog Scale for Pain (VAS Pain), Numeric Rating Scale for Pain (NRS Pain), McGill Pain Questionnaire (MPQ), Short-Form McGill Pain Questionnaire (SF-MPQ), Chronic Pain Grade Scale (CPGS), Short Form-36 Bodily Pain Scale (SF-36 BPS), and Measure of Intermittent and Constant Osteoarthritis Pain (ICOAP). Arthritis Care Res (Hoboken). 2011;63(11):240-52.

16. Kocyigit H, Gulseren S, Erol A, Hızlı N, Memis A. The reliability and validity of the Turkish version of Quality of Life Questionnaire of the European Foundation for Osteoporosis (QUALEFFO). Clin Rheumatol. 2003;22(1):18-23.

17. Tunca Yılmaz O, Yakut Y, Uygur F, Ulug N. Tampa Kinezyofobi Ölçeği’nin Türkçe versiyonu ve test-tekrar test güvenirliği. Turkish version of the Tampa Scale for Kinesiophobia and its test-retest reliability. Fizyoter Rehabil. 2011;22(1):44-49.

18. Gregg CD, McIntosh G, Hall H, Watson H, Williams D, Hoffman CW. The relationship between the Tampa Scale of Kinesiophobia and low back pain rehabilitation outcomes. The Spine Journal: Official Journal of the North American Spine Society. 2015;15(12):2466-2471.

19. Koho P, Aho S, Watson P, Hurri H. Assessment of chronic pain behaviour: reliability of the method and its relationship with perceived disability, physical impairment and function. J Rehabil Med. 2001;33:128/132. 
20. Swinkels-Meewisse IE, Roelofs J, Verbeek AL, Oostendorp RA, Vlaeyen JW. Fear of movement/(re)injury, disability and participation in acute low back pain. Pain. 2003; 105:371-379.

21. Fishbain DA, Cole B, Lewis JE, Gao J. Antidepressant Depression Treatment Response and Remission in Patients with Depression and Pain? An Evidence-Based Structured Review. Pain Med. 2014 Sep;15(9):1522-39.

22. Knapik A, Saulicz E, Gnat R. Kinesiophobia introducing a new diagnostic tool. J hum Kinet. 2011;28:25-31.

23. Gunendi Z, Eker D, Tecer D, Karaoglan B, Ozyemisci-Taskiran O. Is the word "osteoporosis" a reason for kinesiophobia? Eur J Phys Rehabil Med. 2018 Oct;54(5):671-675.

24. Pereira LS, Sherrington C, Ferreira ML, Tiedemann A, Ferreira $\mathrm{PH}$, Blyth FM, et al. Self-reported chronic pain is associated with physical performance in older people leaving aged care rehabilitation. Clin Interv Aging. 2014;14(9):259-65.

25. Jarvinen TL, Sievanen H, Khan KM, et al: Shifting the focus in fracture prevention osteoporosis to falls. BMJ. 2008; 336:124126.

26. Gold DT. The nonskeletal consequences of osteoporotic fractures. Psychologic and social outcomes. Rheum Dis Clin North Am. 2001;27: 255-62.

27. Hallberg I, Rosenqvis AM, Kartous L, Löfman O, Wahlström O, Toss G. Health-related quality of life after osteoporotic fractures. Osteoporos Int. 2004;15:834-841.

28. Kanis JA, Minne HW, Meunier PJ et al. Quality of life and vertebral osteoporosis. Osteoporosis Int. 1992;2: 161-3.

29. Nur H, Toraman NF. Postmenopozal osteoporozda vertebral k1rıkların yaşam kalitesine etkisi. Turk J Osteoporos. 2011;17:814.

30. Başaran S, Güzel R, Benlidayı İC, Uysal FG. Postmenopozal ve senil osteoporozlu kadınlarda yaşam kalitesinin ve belirleyicilerinin değerlendirilmesi. Turk J Phys Med Rehab. 2006;52:31-6.

31. Oksuz s, Unal E. The effect of the clinical pilates exercises on kinesiophobia and other symptoms related to osteoporosis: Randomised controlled trial. Complement Ther Clin Pract. 2017;26:68-72.

32. Gianoudis J, Bailey CA, Ebeling PR, Nowson CA, Sanders KM, Hill K, et al. Effects of a targeted multimodal exercise program incorporating high-speed power training on falls and fracture risk factors in older adults: a community based randomized controlled trial. J Bone Miner Res. 2014;29:182-91.

33. vAveiro MC, Avila MA, Pereira-Baldon VS, Ceccatto Oliveira ASB, Gramani-Say K, Oishi J, et al. Water versus land-based treatment for postural control in postmenopausal osteoporotic women: a randomized, controlled trial. Climacteric. 2017;20:427-35. 